\title{
SISTEMA INTEGRADO DE TRATAMENTO DE EFLUENTES SANITÁRIOS COM REATORES ANAERÓBIOS SEQUENCIAIS EM BATELADA E WETLANDS CONSTRUÍDOS DE FLUXOS ALTERNADOS
}

\author{
Gustavo Stolzenberg Colares ${ }^{1}$, Fagner Pereira da Silva ${ }^{2}$, Gleison de Souza Celente ${ }^{1}$, Julia Fernanda Radkte ${ }^{3}$, Enio Leandro \\ Machado ${ }^{4}$. \\ 1 Programa de Pós-Graduação em Tecnologia Ambiental, UNISC, CEP 96815-900, Santa Cruz do Sul, Brasil. \\ 2 Curso de Engenharia Ambiental, UNISC, CEP 96815-900, Santa Cruz do Sul, Brasil. \\ 3 Curso de Química, UNISC, CEP 96815-900, Santa Cruz do Sul, Brasil. \\ 4 Departamento de Química e Física, Programa de Pós-Graduação em Tecnologia Ambiental, UNISC, CEP 96815-900, Santa Cruz \\ do Sul, Brasil.
}

*E-mail: gutuscs@hotmail.com

\section{RESUMO}

A concepção de um sistema integrado de wetlands construídos (WCs), de diferentes configurações, foi desenvolvida neste trabalho visando melhorias para remoção de nitrogênio e fósforo de efluentes de águas negras e amarelas, bem como da não utilização de suporte fixo para plantio das mudas de Hymenachne grumosa em parte do sistema. Canos de PVC foram utilizados em parte para montagem do sistema nas unidades de wetlands construídos flutuantes de fluxo horizontal + flutuantes de fluxo alternado + de fluxo vertical. No último estágio foram aplicadas britas de números 1 e 2 para o sistema suporte. Os estudos foram feitos no campus da Universidade de Santa Cruz do Sul - UNISC, RS. As taxas de aplicação de Carbono Orgânico Total (COT), nitrogênio amoniacal e fósforo solúvel foram controladas para não ultrapassar respectivamente os limites de $26,1,2 \mathrm{e} 0,2 \mathrm{~g} \mathrm{~m}^{-1} \mathrm{dia}^{-1}$ nos três sistemas integrados, considerando tempo de detenção de 7 dias para cada compartimento. As disposições das macrófitas foram de 24 até 32 mudas m$^{-2}$, sendo que lentilhas (Lemna sp.) e alfaces d'água (Pistia stratiotes) foram utilizadas para controle de espaços em aberto na superfície do líquido nas configurações flutuante de fluxo horizontal (WCFFH) e flutuante de fluxo horizontal alternado (WCFFA). Os resultados revelaram

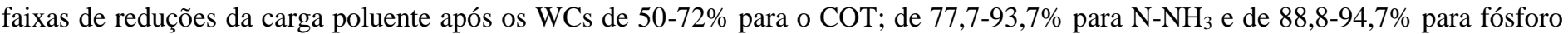
solúvel. O desenvolvimento do sistema radicular das macrófitas dos sistemas flutuantes ainda não atingiu a potencial plenitude de até $40 \mathrm{~cm}$, sendo, portanto, possíveis melhores resultados com o decorrer dos estudos.

Palavras-chave: Saneamento rural. Sistema Híbrido. Esgoto Sanitário. Tratamento Descentralizado. Eutrofização.

\section{Introdução}

O cenário do saneamento básico no Brasil apresenta ainda diversas fragilidades, mesmo com a evolução nos índices de coleta e tratamento de efluentes líquidos. Estes serviços ainda encontram-se aquém do esperado quando comparados aos mesmos índices de países mais desenvolvidos [1]. Esta eficiência está intimamente ligada à qualidade e a expectativa de vida de uma sociedade, e, segundo a Organização Mundial da Saúde (OMS), os investimentos na esfera de saneamento básico acarretam ainda diversos benefícios ambientais como a prevenção da poluição e a recuperação de nutrientes, bem como benefícios econômicos, tais como ganhos em turismo, valorização de terras e da pesca. Segundo a mesma, cada dólar investido em saneamento gera uma economia em média de 4 dólares em serviços hospitalares [2].

No Brasil, um dos potenciais investimentos para saneamento de esgotos são as experiências com wetlands construídos, que se iniciaram na década de 1980, ampliando-se na década de 1990 e se intensificando a partir dos anos 2000, quando esses sistemas começaram a distribuir-se por todo o território nacional, porém com variados projetos, utilizando-se diversas configurações de materiais filtrantes e macrófitas empregadas [3]. 
Os WCs de fluxos vertical (WCFV) e horizontal subsuperficial (WCFHSS) são os mais populares na Europa e nos EUA [4], por não apresentarem contato da lâmina da água com o ambiente externo, prevenindo dessa forma o aparecimento de mosquitos, odores indesejados e acidentes com crianças e animais. Os WCs de fluxo subsuperficial utilizam os mesmos mecanismos de remoção que os WCs de superfície livre, basicamente sedimentação, filtração e degradação microbiológica dos poluentes. Porém, devido à presença de um substrato para suporte (geralmente areia ou brita), o efluente fica constantemente em contato com um meio filtrante, promovendo dessa forma uma maior área superficial para crescimento bacteriano. Sistemas de WCFV são menos comuns que os de fluxo horizontal, e geralmente são operados em batelada para que o filtro não fique sempre saturado, possibilitando a transferência de oxigênio atmosférico por difusão [5].

Já os Wetlands Construídos de fluxo superficial livre (WCSL), em contrapartida, apresentam a superfície da água diretamente exposta à atmosfera. Suas principais vantagens são: menores custos em relação aos WCs de fluxo subsuperficial, devido a não necessidade de material suporte, se assemelhando mais aos ambientes naturais. Assim, possibilitam hospedar mais a fauna nativa [6], além de não ocorrer a colmatação do meio filtrante, sem perder, portanto, condutividade hidráulica com o tempo, e por último, o maior contato existente do sistema radicular das macrófitas com o efluente [7].

Existe ainda um sistema mais recente, denominado Filtro de Macrófitas Flotadas (Floating Macrophyte Filter), que integra pontos positivos de ambos os sistemas com fluxo subsuperficial e com o de superfície livre. Em suma, esses filtros são compostos por um material flutuante juntamente com suporte para macrófitas, o qual irá manter suspensas as plantas emergentes ao invés das naturalmente flutuantes, sustentando as mesmas e mantendo em contato com o efluente apenas as suas raízes. De uma forma geral, quanto maior a fração submersa das raízes melhor será a eficiência do sistema no tratamento [7].

Em relação a remoção de nitrogênio total, os WCSL alternando zonas com raízes e zonas profundas foram efetivos, devido a alternância de zonas anóxicas com zonas mais óxicas em função do contato com a atmosfera e bem como do transporte de oxigênio através das raízes das macrófitas empregadas, e dessa forma favorecendo a nitrificação [6]. Os sistemas com superfície livre têm se mostrado promissores para remoção de sólidos suspensos totais (com índices superiores a 80\%) através dos processos de floculação e decantação, e podendo colaborar na redução de $\mathrm{DBO}_{5}$ e nutrientes, quando aplicado um tempo de detenção hidráulico (TDH) superior a 4 dias.

A decisão da macrófita empregada deve considerar principalmente fatores de adaptação das mesmas a região em estudo, como as características climáticas, especialmente temperatura e precipitações médias, bem como condições das configurações dos sistemas para o seu desenvolvimento [8].

Em virtude disso no presente estudo foram utilizadas incialmente três espécies de macrófitas, a do tipo emersa $H$. grumosa, já utilizada por diversos autores, sendo uma planta nativa da região e demonstrando previamente eficiência para o tratamento de águas residuárias [9-11]. As outras duas macrófitas utilizadas foram do tipo flutuante, a Lemna sp. assim como a Pistia stratiotes (conhecidas por lentilha e alface d'água, respectivamente). Apesar de serem utilizadas na despoluição de águas residuárias, a biomassa produzida pode possuir ainda diversas finalidades após o seu uso, tais como forragem para animais (peixes, suínos e aves), obtenção de adubo e de biogás [12].

Entretanto, para este trabalho, as macrófitas flutuantes foram utilizadas visando principalmente o recobrimento da lâmina da água, reduzindo significativamente seu contato com o ar. Essas macrófitas são utilizadas para mitigar a proliferação de larvas de pernilongos no local [13], bem como impedir o crescimento e a propagação de algas na primeira e na segunda caixa (reduzindo a passagem de luz), por serem de superfície livre.

O objetivo desse estudo foi de desenvolver sistema integrado de WCs em regime de batelada de diferentes configurações: flutuante de fluxo horizontal (WCFFH) + flutuante de fluxo horizontal alternado (WCFFA) + fluxo vertical (WCFV) para o tratamento de efluentes sanitários de campus universitário, visando principalmente à remoção de nitrogênio total e fósforo solúvel de efluente do pré-tratamento com reatores anaeróbios em batelada.

\section{Metodologia}

\subsection{Unidade de Tratamento}

A unidade experimental do trabalho desenvolvido localiza-se na Estação de Tratamento e Efluentes da Universidade de Santa Cruz do Sul, cuja configuração pode ser visualizada na Figura 1.

Os reatores anaeróbios em batelada sequenciais (RAs) apresentados na ilustração da Figura 1 são de volume útil de 100 L, precedidos de um tanque de sedimentação (TS) de volume útil de 100 L. O tempo de detenção no conjunto TS + RAs é de 7 dias, bem como nos WCs, totalizando 28 dias de TDH para o tratamento inteiro. O volume útil de $90 \mathrm{~L}$ está associado com o WCFFH e com o WCFV. Para o WCFF, o volume útil é de 200 L. Nos estágios WCFFH e WCFFA, a densidade das mudas plantadas é de $32 \mathrm{~m}^{-2}$. Nos espaços vazios Pistia stratiotes e lemna sp. foram dispostas. 

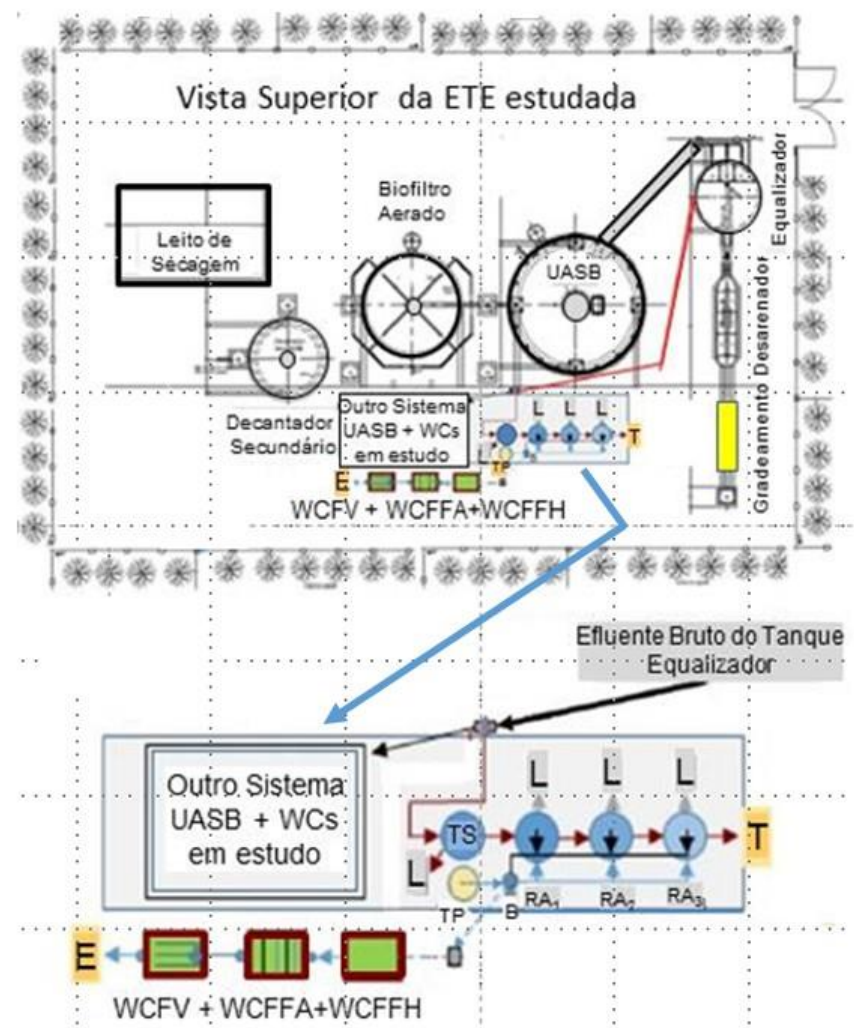

Figura 1 - Disposição dos Reatores Anaeróbios em Bateladas Sequenciais e dos WCs. $\mathrm{L}=$ Lodo; $\mathrm{TS}=$ Tanque Sedimentador; $\mathrm{B}=\mathrm{Bomba}$; RA = Reator Anaeróbio; $\mathrm{T}=$ Efluente tratado por anaerobiose; $\mathrm{TP}=$ Tanque pulmão; $\mathrm{E}=$ Efluente final. Fonte: Elaboração Própria.

\subsection{Caracterizações Analíticas}

As amostragens foram feitas na unidade da Figura 1 considerando o efluente Bruto (B) e os efluentes dos WCs (W1= WCFFH; W2 = WCFFA; W3 = WCFV). A cada sete dias, foram coletadas amostras e analisados os seguintes parâmetros: Carbono Orgânico Total (COT), N-NH $\mathrm{N}_{3}$, fósforo solúvel e turbidez. Os procedimentos foram realizados de acordo com o Standard Methods [14]. Para as determinações de COT foi usado o analisador Shimadzu TOC-L CSH/CPH, aplicando-se pré filtração com filtro $0,45 \mu \mathrm{m}$.

\subsection{Detalhamento de aspectos de operação}

O desenvolvimento operacional do sistema envolveu quatro meses, e nesse período considerou-se como facilitar a carga e descarga dos efluentes das unidades TS e RAs. Uma bomba centrífuga de $1 \mathrm{CV}$ foi utilizada com distribuidores do efluente deste sistema para quatro linhas de configurações, sendo três de outros estudos não apresentados aqui. Durante o TDH de 7 dias, foi adotada uma taxa de recirculação dos efluentes de $1 \mathrm{~m}^{3} \mathrm{~h}^{-1}$ (ou seja, no terceiro dia de digestão anaeróbia). O cuidado principal foi o de garantir a distribuição dos efluentes dos RAs para as linhas de estudo, ao mesmo tempo, não permitindo assim diferenças da carga de material sedimentado ao final de 7 dias contidos nas bombonas. $\mathrm{O}$ volume útil de $100 \mathrm{~L}$ para cada bombona garante a não transferência do lodo da zona de sedimentação.

\section{Resultados e discussões}

\subsection{Sistema Integrado de WCs}

A primeira caixa no sistema integrado é caracterizada como um WCFFH, na qual foram empregadas as macrófitas $H$. grumosa juntamente com macrófitas da espécie $P$. stratiotes (conhecida por alface d'água). Enquanto a última espécie é uma macrófita flutuante, utilizada nesse estudo visando à cobertura da superfície para combater a proliferação de pernilongos e de microalgas na água, a $H$. grumosa é uma espécie emersa. Inicialmente, foi utilizada também a macrófita Lemna sp., porém, a mesma não conseguiu se adaptar as condições do sistema e não foi capaz de cobrir a área como planejado, cedendo espaço a alface d'água. Dessa forma, foi desenvolvido um sistema suporte nessa caixa para sustentar essas macrófitas emergentes na superfície da água, para que as mesmas flutuassem.

O primeiro sistema flutuante elaborado foi confeccionado utilizando-se uma placa de acetato-vinilo de etileno (EVA), onde foram efetuados furos, nos quais foram encaixados pequenos suportes para mudas, vazados e preenchidos com brita número 2, onde foram fixadas as macrófitas. Entretanto, com o passar do tempo, o EVA demonstrou-se um material pouco resistente a ação do sol e ao peso submetido, deformando-se e comprometendo o crescimento das plantas. Por essa razão, o sistema utilizado foi substituído por flutuador de polietileno expandido, cano PVC e tubetes cônicos de plástico, onde as plantas foram fixadas com a ajuda de brita números 1 e 2 . Um sistema semelhante foi aplicado também à caixa W2, contendo também a associação das mesmas macrófitas de W1.

A densidade de plantas para a primeira e a segunda caixa foi realizada segundo recomendação da literatura para H. grumosa [9], a qual indicou uma quantidade de 32 mudas por metro quadrado. Essa proporção foi utilizada na primeira e na segunda caixa, porém na terceira, a densidade de plantas foi reduzida para 24 mudas $/ \mathrm{m}^{2}$ por ser considerada suficiente em um primeiro momento. Apesar das análises das amostras terem começado apenas em janeiro de 2017, já foi possível identificar alguns comportamentos em termos de eficiência de remoção dos parâmetros estudados. 
A Figura 2 apresenta os valores das análises de $\mathrm{N}-\mathrm{NH}_{3}$. Os resultados obtidos, até o presente momento, demonstram uma boa eficiência do sistema na remoção de $\mathrm{N}$ amoniacal com características de aumento de eficiência, na medida em que o sistema radicular cresce. Conforme pode ser visualizado na Figura 2, após o W3 não se detectou $\mathrm{N}-\mathrm{NH}_{3}$ nas análises, resultado superior ao de outros sistemas híbridos estudados, que verificaram remoção de $86 \%$ [15], $69.5 \%$ [16] e semelhante ao verificado por [17]: $98 \%$ de remoção.

Um dos fatores que promove bastante a remoção de $\mathrm{N}$ amoniacal do efluente é a altura relativamente baixa adotada nos WCs, uma vez que um ambiente óxico favorece o processo de nitrificação [18]. A entrada de oxigênio nos WCs estudados ocorre principalmente através da difusão atmosférica no líquido e pelo contato direto do efluente com as raízes. Logo, é interessante para remoção de amônia que as raízes tenham comprimento suficiente para alcançar toda a profundidade dos WCs [19].

O tanque compartimentado do W2 confere potencialidade de sistema óxico/anóxico, permitindo dessa forma mecanismo de eliminação como $\mathrm{N}_{2}$ ou $\mathrm{N}_{2} \mathrm{O}$ para o nitrogênio.

Já em relação ao fósforo, outro nutriente e parâmetro com destaque para o presente trabalho, observou-se eficiência da etapa do Wetland construído de fluxo vertical (WCFV-W3), conforme pode ser observado na Figura 3.

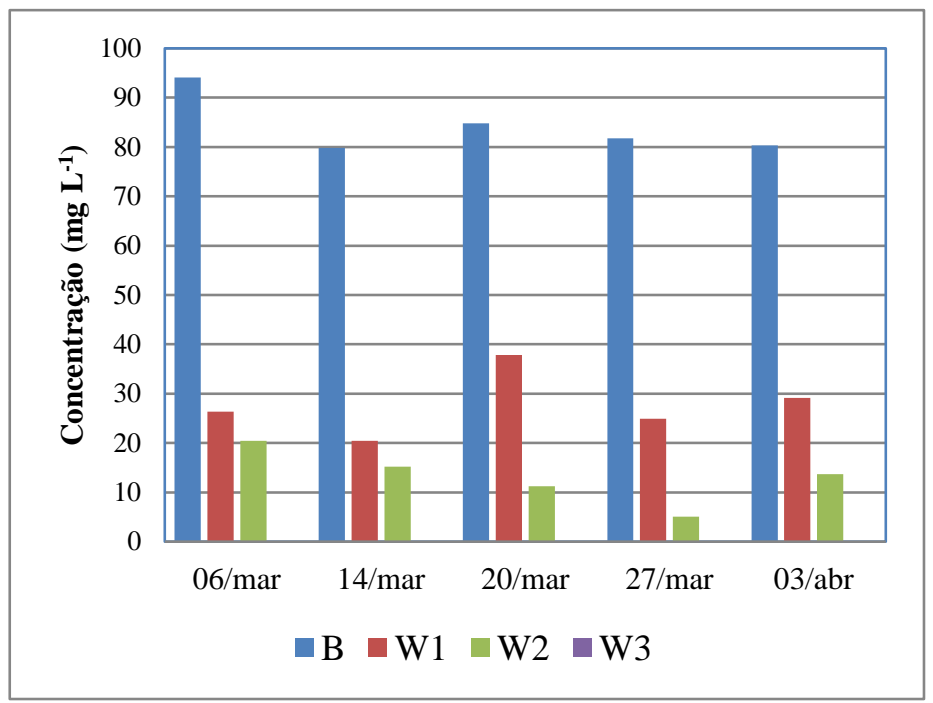

Figura 2: Resultados das análises referentes ao Nitrogênio amoniacal.

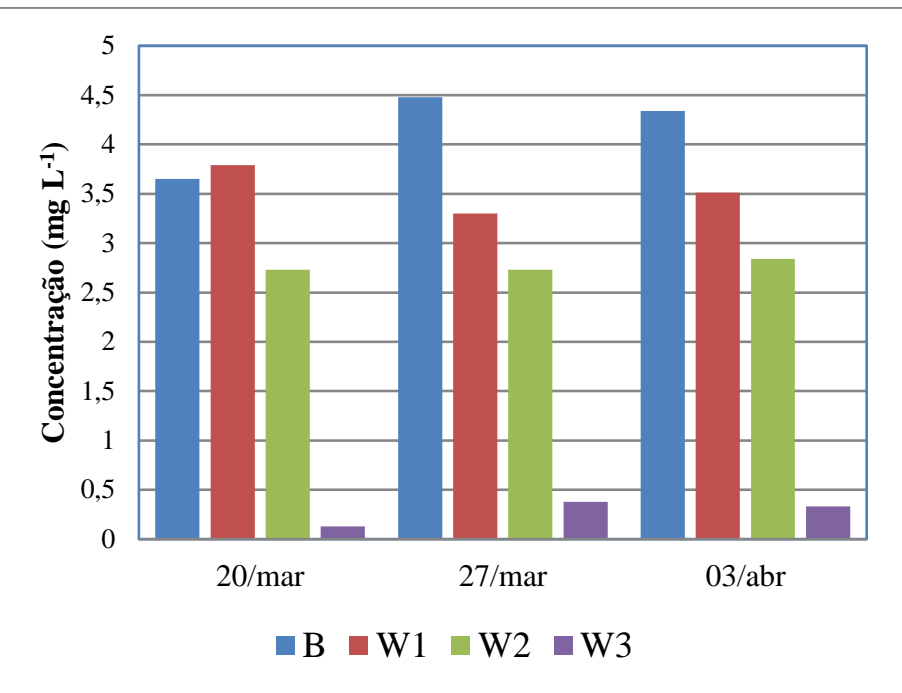

Figura 3 - Resultados das primeiras análises em relação a concentração de Fósforo solúvel no efluente.

Os resultados obtidos em relação ao fósforo solúvel estão de acordo com os valores verificados em outro estudo de sistemas de WCs híbridos no Brasil, que apresentou valores médios de remoção de 68\% [20]. Estudos verificaram que WC híbridos na China apresentam em média remoção de $79,68 \%$ de remoção de fósforo total [21]. É importante destacar o fato de que o terceiro estágio (WCFV-W3) foi o mais eficiente dos três, o que é justificado pela indicação de que a adsorção no substrato seja o principal mecanismo de remoção de fósforo em WCs, e que esse estágio é o único com material suporte filtrante (brita). Além da adsorção, outros mecanismos presentes são o armazenamento nas biomassas vegetal e microbiológica e a precipitação de compostos insolúveis [21].

Em um experimento, combinando reator UASB com WCs de Fluxo Horizontal, os autores observaram que a contribuição direta das macrófitas utilizadas na remoção de fósforo gira em torno de 7 a 30\% apenas, o que demonstra coerência dos baixos resultados obtidos pelas caixas W1 e W2, que não apresentam material filtrante [22].

A maior eficiência na remoção de fósforo do terceiro estágio (WCFV) pode ter ocorrido também, devido ao fato do mesmo receber uma carga de poluentes mais baixa em relação aos outros (aprox. 0,06 $\mathrm{g} \mathrm{m}^{-2} \mathrm{dia}^{-1}$ para o WCFV, assim como também devido ao TDH, que chega a 7 dias somente na última caixa). 
O desempenho do sistema com relação a redução de Carbono Orgânico Total (COT), conforme a Figura 4, não apresentou resultados muito satisfatórios.

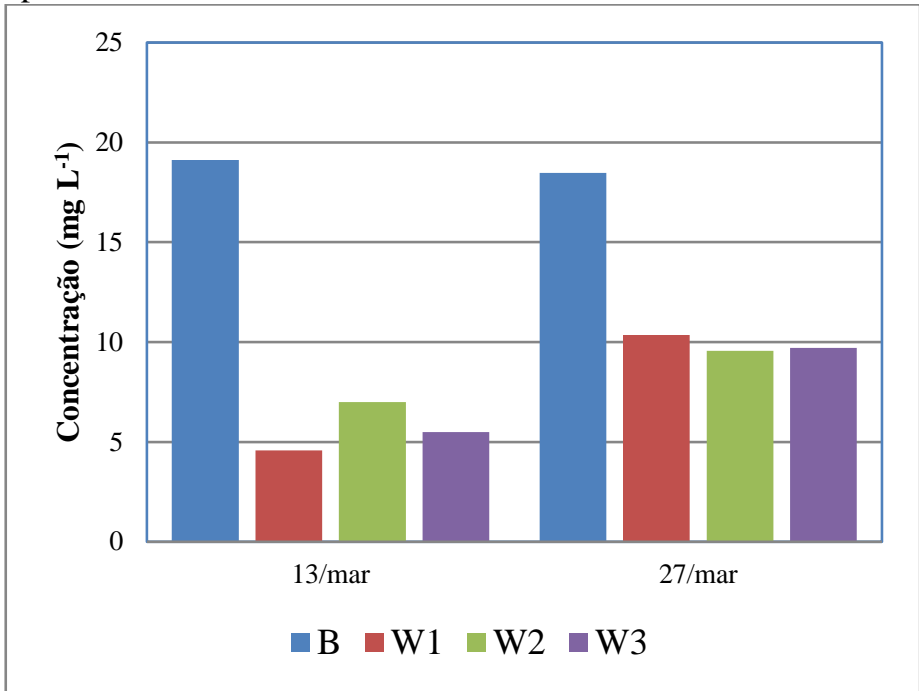

Figura 4 - Resultados referentes ao Carbono Orgânico Total (COT).

A taxa de aplicação de COT foi de $0,25 \mathrm{~g} \mathrm{~m}^{-1} \mathrm{dia}^{-1}$ no WCFV. Conforme pode ser visualizado na Figura 4, os resultados verificados ficaram abaixo do esperado (61\% em média) quando compara-se aos valores de remoção verificados em outros sistemas híbridos, como $95 \%$ por [15] e $80.1 \%$ [23] para $\mathrm{DBO}_{5}$ e de $87 \%$ para DQO por [20].

Filtros de Macrófitas flotadas podem apresentar altas eficiências de remoção de matéria orgânica devido ao alto contato do efluente com o sistema radicular das macrófitas, principalmente pela ação dos microrganismos aderidos as raízes [7]. Neste caso, o melhor desenvolvimento do sistema radicular é fundamental para remover a fração solúvel de carbono presente nos efluentes.

Quanto a turbidez, o sistema integrado em estudo tem se mostrado extremamente eficiente, atingindo taxas de remoção superiores a $90 \%$. Isso decorre, possivelmente, devido as ações de floculação e decantação da primeira caixa (W1), que pode apresentar comportamento de um decantador, enquanto a última caixa (W3), devido à presença da brita, pode atuar como um polimento. As Figuras 5 e 6 apresentam um registro fotográfico das amostras antes das análises e os resultados obtidos para turbidez, respectivamente.

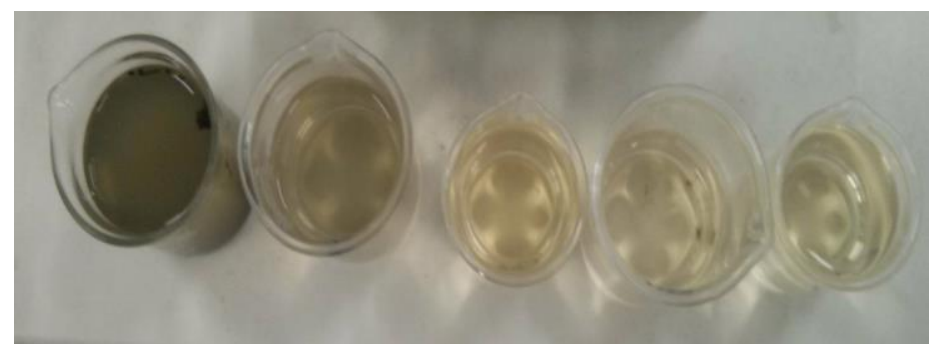

Figura 5 - Registro Fotográfico com as amostras: Esgoto Bruto (E), amostra pós reatores anaeróbios, amostra pós W1, amostra pós W2 e amostra pós W3 (efluente final). Fonte: Autores

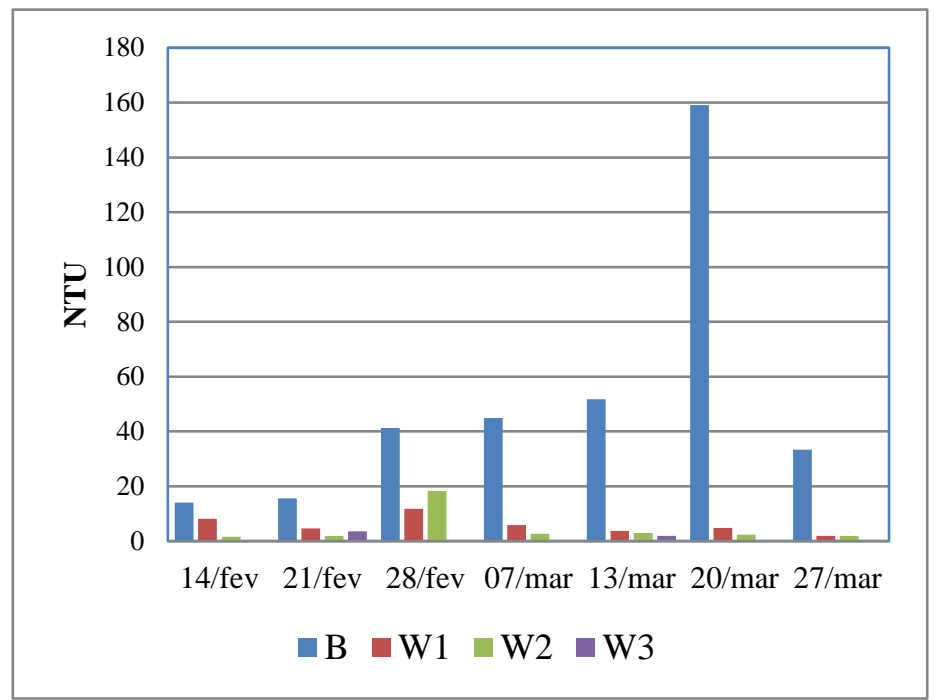

Figura 6 - Resultados obtidos a partir das análises de turbidez das amostras associadas com registro fotográfico.

De uma forma geral, WCs são altamente eficientes para redução de turbidez em efluentes. Em experimentos realizados no Brasil com um sistema híbrido (WCFV + WCFH), os autores verificaram reduções de turbidez do efluente bruto com média de 122 NTU para valores inferiores a 5 NTU para o efluente tratado [17].

\section{Conclusões}

Os resultados obtidos com o sistema integrado WCFFH+ WCFFA+ WCFV foram satisfatórios, principalmente em termos de remoção $\mathrm{N}-\mathrm{NH}_{3}$, fósforo solúvel e turbidez. Considerando a simplicidade de projeto, construção e manutenção, bem como potencial baixo custo, o sistema apresenta um grande potencial para aplicação em zonas rurais e/ou de baixa densidade populacional. É importante destacar também que as diferenças encontradas nos resultados das análises (principalmente no efluente bruto) entre os meses de fevereiro e de março ocorreram devido ao início do semestre letivo, momento no qual ocorreu um aumento significativo de pessoas na universidade. 
Espera-se que nos meses posteriores aos resultados obtidos, até o presente momento, o sistema possa apresentar-se mais eficiente no tratamento dos efluentes (principalmente em relação a remoção de COT), devido ao desenvolvimento do sistema radicular das macrófitas, uma vez que as mudas utilizadas eram relativamente novas e possuíam raízes pouco desenvolvidas.

\section{Agradecimentos}

Os autores gostariam de agradecer à Universidade de Santa Cruz do Sul (UNISC), à coordenação do Programa de PósGraduação em Tecnologia Ambiental (PPGTA), à Coordenação de Aperfeiçoamento Pessoal de Nível Superior (CAPES) e ao Conselho Nacional de Desenvolvimento Científico e Tecnológico (CNPQ) pelo apoio financeiro e toda a cooperação para a realização desse estudo.

\section{INTEGRATED SYSTEM OF ANAEROBIC REACTORS WITH HYBRID CONSTRUCTED WETLANDS IN BACHT FLOW FOR WASTEWATER TREATMENT}

\begin{abstract}
The conception of an integrated system of Constructed Wetlands (CWs), from different configurations was developed in this paper aiming at improvements for the removal of nitrogen and phosphorus from black and yellow water effluents, as well as the non use of a fixed support for planting the seedlings of lumpy Hymenachne in some parts of the system. PVC pipes were used in pieces in order to assemble the system in the constructed wetland units floating horizontal flow + floating alternating + vertical flow. At the last stage, coarse gravel 1 and 2 were applied for the support system. The studies were carried out in the campus of the University of Santa Cruz do Sul - UNISC, RS. The application rates of Total Organic Carbon (TOC), ammoniacal nitrogen and soluble phosphorus were controlled in order not to exceed respectively the limits of $26,1.2$ and $0.2 \mathrm{~g} \mathrm{~m}$ $1 \mathrm{day}^{-1}$ in the three integrated systems, considering a 7 day time of detention for each compartment. The macrophytic distributions ranged from 24 up to $32 \mathrm{~m}-2$ seedlings, considering that water lentils (Lemna sp.) and water lettuces (Pistia stratiotes) were used to control open spaces on the surface of the liquid on the floating horizontal flow configurations (CWFHF) and alternating horizontal flow floating (CWAFF). The results showed reductions in pollutant load after CWs of $50-72 \%$ for TOC; $77.7-93.7 \%$ for $\mathrm{N}-\mathrm{NH}_{3}$ and $88.8-94.7 \%$ for soluble phosphorus. The development of the root system of floating macrophytes has not reached its plenitude fullness of up to $40 \mathrm{~cm}$ yet, and therefore, better results can be possible along the course of the studies.
\end{abstract}

Keywords: Rural sanitation. Hybrid System. Sanitary sewage. Decentralized Treatment. Eutrophication

\section{Referências}

[1] PARKINSON, J. TAYLER, K.; Decentralized wastewater management in periurban areas in low-income countries. Environment and Urbanization, Vol. 15, n. 1, p. $75-90.2003$.

[2] WORLD HEALTH ORGANIZATION (WHO); Water Global Analysis and Assessment of Sanitation and Drinking-Water - Investing in water and sanitation: increasing access, reducing ineqaulities. . 2014. 98p.

[3] SEZERINO, P. H. et al.; Experiências brasileiras com wetlands construídos aplicados ao tratamento de águas residuárias: parâmetros de projeto para sistemas horizontais. Engenharia Sanitária Ambiental. v.20 n.1. p.151-158. 2015.

[4] WOMEN IN EUROPE FOR A COMMON FUTURE (WECF). Sustainable and cost-effective wastewater systems for rural and peri-urban communities up to 10,000 PE. Hamburgo, 2010. 32p.

[5] TOUSIGNANT, E. FANKHAUSER, O. HURD, S.; Guidence Manual for the design, construction and operations of constructed wetlands for rural applications in Ontario. Guelph, 1999. 164p.

[6] ENVIRONMENTAL PROTECTION AGENCY. Constructed Wetlands Treatment of Municipal Wastewaters. 2000. Disponível em: https://cfpub.epa.gov/si/si_public_record_report.cfm?dirEntryId=64144. Acesso em: 11 ago. 2017.

[7] GONZÁLEZ, J. F. et al.; Manual de fitodepuración: Filtros de Macrófitas en Flotacion. 2005 Disponível em: https://www.fundacionglobalnature.org/macrophytes/documentacion/Cap\%EDtul os\%20Manual/Cap\%EDtulos\%201\%20a\%202.pdf. Acesso em: 11 ago. 2017.

[8] ENVIRONMENTAL PROTECTION AGENCY (EPA). Guiding Principles for Constructed Treatment Wetlands: providing for Water Quality and Wildfire Habitat. 2010. Disponível em: https://nepis.epa.gov/Exe/ZyPDF.cgi/2000536S.PDF?Dockey=2000536S.PDF. Acesso em: 11 ago. 2017.

[9] HORN, T. B. Integração de sistemas wetlands construídos + fotoozonização catalítica no tratamento de efluentes de campus universitário. 2011. 157f. Dissertação (Programa de Pós-graduação em Tecnologia Ambiental - Mestrado) Universidade de Santa Cruz do Sul. 2011

[10] ZERWES, F. V. ; KERN, D. ; LUTTERBECK, C. A. ; KIST, L. T.; MACHADO, Ê. L. . Avaliação citogenética do tratamento com o processo UASB/biofiltro anaeróbio/wetlands construídos de fluxo subsuperficial (WCFSS) de efluentes de propriedade rural. Revista Engenharia e Construção Civil, v. 2, p. 52-60, 2015.

[11] SILVEIRA, Elizandro Oliveira. Sistema integrado reator anaeróbio+microalgas+wetlands construídos no tratamento de efluentes urbanos. 2016. 119f. Dissertação (Programa de Pós-graduação em Tecnologia Ambiental Mestrado) - Universidade de Santa Cruz do Sul, Santa Cruz do Sul, 2016.

[12] POTT, V. J., POTT, A.; Potencial de Uso de Plantas Aquáticas na Despoluição da Água. Campo Grande: Embrapa Gado de Corte. n 1., 2002. 
[13] ENVIRONMENTAL PROTECTION AGENCY Handbook of Constructed Wetlands: Guide to Creating Wetlands for Agricultural Wastewater, Domestic Wastewater, Coal Mine Drainage, Stormwater in the Mid-Atlantic Region, General Considerations. 2013.2 Disponível em: https://www.epa.gov/sites/production/files/2015-10/documents/constructedwetlands-handbook.pdf; Acesso em: 11 ago. 2017.

[14] AMERICAN PUBLIC HEALTH ASSOCIATION (APHA/AWWA); Standard Methods for the Examination of Water and Wastewater. 21. ed. Washington: APHA/AWWA/WEF, 2005.

[15] MASI, F., MARTINUZZI, N.; Constructed wetlands for the Mediterranean countries: hybrid systems for water reuse and sustainable sanitation. Desalination, Vol 215, n. 1-3, p. 44-55. 2007

[16] SINGH, S., et al.; Performance of an anaerobic baffled reactor and hybrid constructed wetland treating high-strength wastewater in Nepal-A model for DEWATS. Ecological Engineering, Vol. 35, n.5, p. 654-660. 2009.

[17] ÁVILA, C., et al.; Integrated treatment of combined sewer wastewater and stormwater in a hybrid constructed wetland system in southern Spain and its further reuse. Ecological engineering, Vol. 50, n.1, p. 13-20. 2013

[18] PAOLI, A. C. de. Análise de desempenho e comportamento de wetlands horizontais de fluxo subsuperficial baseado em modelos hidráulicos e cinéticos. 2010. 165f. Dissertação (Programa de Pós-graduação em Saneamento, Meio Ambiente e Recursos Hídricos. Universidade Federal de Minas Gerais. 2010)

[19] VYMAZAL J.; Horizontal sub-surface flow and hybrid constructed wetlands systems for wastewater treatment. Ecological Engineering, Vol. 25, n. 1, p. 478 490. 2005.

[20] SILVA, M. V.; BUENO, R. F.; Avaliação de um wetland construído híbrido no tratamento de esgoto sanitário. HOLOS Environment. Vol. 15, n. 2, p. 211222,2015

[21] BRIX, H.; Functions of macrophytes in constructed wetlands. Water Science and Technology, Vol. 29, n. 4, p. 78-90, 1994.

[22] CALIJURI, M. L., et al.; Tratamento de esgotos sanitários em sistemas reatores UASB/wetlands construídas de fluxo horizontal: eficiência e estabilidade de remoção de matéria orgânica, sólidos, nutrientes e coliformes. Engenharia Sanitária e Ambiental, Vol. 14, n. 3, p. 421-430, 2009.

[23] ZHANG, D., GERSBERG, R. M., KEAT, T. S.; Constructed wetlands in China. Ecological Engineering, Vol. 35, n. 10, p. 1367-1378. 2009 